\title{
HOW TO IMPROVE INNOVATION CAPABILITY? : THE ROLE OF INTELLECTUAL CAPITAL AND ORGANIZATIONAL MOTIVATION OF MANUFACTURING FIRMS IN SRI LANKA
}

\author{
Sivalogathasan.V \\ Department of Management Studies, Faculty of Humanities and Social Sciences \\ The Open University of Sri Lanka \\ Nawala, Nugegoda, Sri Lanka
}

\begin{abstract}
The intellectual capital creates a crucial factor for the achievement of the innovation of firm. Numerous studies have been documented that intellectual capital positively influences innovation capability, which is conceptualized as the degree to achieve its firm performance. However, there is a lack of studies examining the specific means through which organizational motivation influences innovation capability at firm level. Therefore, the purpose of this study is to exhibit the Intellectual capital effects on firm innovation capability by influence the organizational motivation. This study investigates the multidimensional and contingent gradual effect of intellectual capitals and organizational motivation on innovation capability. Manufacturing sectors have shown commendable progress over the past few decades in Sri Lankan. The structured questionnaires were administrated as a research instrument and random sampling technique was used to collect the data from 462 senior executives and senior managers from manufacturing firms in Sri Lanka. The study revealed that the intellectual capital have significant positive relationship on innovation capability with strong influence of organizational motivation. The intellectual capital mediated by organizational motivation that lies outside and inside of the firm have an indirect effect on innovation capability. The findings of this study will be useful for manufacturing industry to apply intellectual capital management and identify organizational motivation to create innovation in their organizations.
\end{abstract}

Keywords: Intellectual capitals, Innovation capability, Organizational motivation 


\section{INTRODUCTION}

The development of intellectual capital can be regarded as an accumulative process which not only creates incentives to be exploited by product innovations, but also delivers the required complementary assets. The development of new products expands a firm's competence base, which in turn, enables further product innovations (Danneels, 2002). Thus, in contrast to incremental innovations or product enhancements, continuous new product developments permit the renewal of organizational resources and can contribute to the building up of dynamic capabilities (Teece 2007; Eisenhardt and Martin, 2000). In particular, intellectual capital are considered to be the most important source of firm's innovativeness and heterogeneity of performance because of relatively high barriers to duplication. On the other hand, the Dynamic Resource-Based View and the Dynamic Capabilities Approach while explaining how firms gain innovation capability and better performance in increasingly demanding environment emphasize dynamics and evolution of resources and capabilities.

Intellectual capital is the value driver of an enterprise and most valuable assets of the firm . Intellectual capital are complex constructs which can be classified into human, organizational, and social capital . While all three dimensions are sources of firm innovation capability, however they are not equally important. The theoretical considerations indicate that human capital is central to intangibles since it is the source of innovation and renewal (Stewart, 1997). However, the empirical research shows mixed results. For example, found that human capital without the support of organizational capital is practically useless, and confirmed that the more important role of organizational capital for firm performance. Still more empirical research are needed to investigate the importance of different intangibles categories for innovation capability and firm performance. In this context the challenge appears to investigate the importance of different intellectual capital dimensions for firm innovation capability.

With a significant contribution of $30 \%$ to the GDP and $25 \%$ to the workforce, the industrial sector in Sri Lanka has become the prime force of value creation in the economic development of the country. Out of four sub sector of industrial sector; Mining \& Quarrying, Manufacturing, Electricity, Gas, \& Water, and Construction. The 
manufacturing sector accounted for over $60 \%$ of the output of the industrial sector and $17 \%$ of the country's GDP. As such the manufacturing sector has become the biggest contributor to the industrial growth of the country. Its contribution of $75 \%$ to national export earnings (USD 7,992) in 2011, has made the manufacturing sector more significant in the Sri Lankan economy.

The Strategy and focus of the government is to ensure that Sri Lanka's industrial sector will be a highly value added, knowledge based, internationally competitive and diversified sector which employs a highly paid, skilled workforce by 2020 . The sector expected to mobilize more local raw material and have a large value creation particularly for a growing economy. Accordingly, Sri Lanka promotes resource based industries which utilized local raw materials \& increase more value addition, as well as technology intensive industries which adopt $\&$ apply advanced technologies.

However, when compared to with East Asian countries such as South Korea, Taiwan, and China, Sri Lanka has to perform much better than before in order to reach their levels of achievement in industrialization and innovation. The ability to reach this level depends not only on the expansion of the manufacturing sector but more importantly on the success innovation of individual manufacturing sector in the country. It is also evident that the success of manufacturing sector is crucial for the country's economic development. However, it is common occurrence throughout the world that innovation is very important to sustainable business. Therefore, it is important to find out through the systematic empirical study, the success factors that would contribute to innovation and success of manufacturing sector in Sri Lanka.

The knowledge required for manufacturing industry to remain competitive in the global trade of manufacturing can be classified as knowledge in design and product development, technical knowledge and market knowledge. In Sri Lanka, industry today lacks with market knowledge as not much market researches are carried out related to Sri Lankan industry . Industry is also not much concern about the research and development activities as well most of the manufacturing organizations are not involved in marketing activities. Traditional low labour cost advantage is now moved to other countries such as Vietnam and Bangladesh causing 
decrease in contribution of manufact uring industry for national economy mainly in terms of the employment . Therefore, knowing what constitutes new sources of competitive advantage and how these factors could be generated is critically important to set a future direction for Sri Lankan manufacturing industry.

Managing intellectual capital is an ongoing challenge, especially as social, political and economic events take their role. Strategies must continually be redefined to deliver improved return on investment in intellectual capital. The Sri Lankan manufacturing industry being the largest contributor to the Sri Lankan economy for last few decades, it should cultivate its competitive advantage in order to be sustainable in the global market. Therefore, the primary objectives of study are: To examine the Intellectual capital (IC) and Organiza tional Motivation (OM) as a critical success factors in Innovation capability $(\mathrm{InC})$ of the manufacturing Industry in Sri Lanka, and to analysis the mediate effect of Organizational Motivation between intellectual capital and Innovation Capability.

\section{LITERATURE REVIEW}

\subsection{Intellectual Capital}

The economic importance of intellectual capital has long been recognized. However, it is recently that it has become the field of research. Intellectual capital research is strongly grounded in practice . Early research on intellectual capital focused extensively on their definitions and classifications. Consequently, in the literature neither one unified definition of intellectual capital nor one general classification can be found. Stewart (1997) illustrated intellectual capital as the sum of an organization's patents, processes, employees' skills, technologies, information about customers and suppliers, and oldfashioned experience. The very common view is that intangibles are contained in the difference between market and book value of the firm.

Regarding contemporary classification schemes of intellectual capital, divides intellectual into three groups: (1) employee competence (individual's ability to act in a wide variety of situations to create both tangible and intellectual capital); (2) internal structure (patents, concepts, models, computer and administrative systems, ex. organizational structure or spirit); (3) external structure (relationships with 
customers, suppliers, brand names, trademarks, organizational reputation and image). Another classification scheme divides intangible resources into assets and skills . The widely accepted classification of intellectual capital is the distinction between human capital, organizational capital and social capital (Stewart, 1997; Bontis, 1998). This classification will be applied for the purposes of the research.

Human capital represents the individual knowledge stock of an organization as represented by its employees (Bontis, Keow and Richardson, 2000). It compromises the competence, skills and intellectual agility of the individual employees ( and it cannot be owned by the company (Bontis, 2001). It is considered to be the most important intellectual asset as it is the source of innovation and renewal (Stewart, 1997).

Organizational capital is everything that gets left behind at the office when employees go home. Firms in order to share the knowledge need structural assets, such as information systems, laboratories, competitive and market intelligence and management focus (Stewart, 1997). On the contrary to human capital, organizational capital belongs to organization as a whole and it can be reproduced and shared. Organizational capital is a critical link that allows intellectual capital to be measured at the organizational level of analysis (Bontis, Keow, Richardson, 2000).

Social capital of the firm is the value of its franchise, its ongoing relationships with people or organizations to which it sells (Stewart, 1997). The main content of social capital are the knowledge of marketing channels and customer relationships (Bontis, 1998). Social capital is more often measured and counted than human and organizational capital. The ultimate form of social capital is shared knowledge (Stewart, 1997).

This study treats intellectual capital as holistic construct (takes into account all of its different aspects rather than focusing on three dimensions) but examines its different aspects separately since difference forms of intellectual capital may have different implications for enhancing motivating factor. A firm's capacity to develop and apply its expertise and knowledge is highly related to its intellectual capital. The most commonly given definition for intellectual capital delineates this 
concept as the overall knowledge and capabilities that an organization can use in order to achieve a competitive advantage) described intellectual capital simply: that is the pillars of the future of any enterprise; it's an indicator of whether an enterprise can operate effectively. Any enterprise that does not invest in invisible capital cannot possibly generate the momentum of innovation.

\subsection{Organizational Motivation}

The effects of Intellectual capital on Innovation capability and firm competitive advantage should be mediated by organizational motivation of internal and external factors. This argument is consistent with the work of who claim that firms that focus extensively on learning from and exploring the environment can constantly renew their knowledge stock but cannot benefit from it unless they can exploit what they have learned from their environment. Similarly, in his seminal work on the role of exploration and exploitation in organizational motiva tion, notes that Adaptive systems that engage in exploration to the exclusion of exploitation are likely to find that they suffer the costs of experimentation without gaining many of its benefits. They exhibit too many underdeveloped new ideas and too little distinctive competence.

Organizational motivation and institutional forces might influence the progress of an organization's Innovation capability and firm performance. King et al (1994) identify two forms of institutional interventions (reputation status and government support) and two innovation drivers (cost efficiency and market share). Reputation status can change the behaviour of those under the institution's way. This can be achieved either without direct use of corporate strategy; with the exercise of social acceptance or by corporate social responsibility. On the other hand, cost efficiency have the purpose of directly and at times indirectly affecting the behaviour of entities. This can be done through low cost or cost reduction that limit options and modify behaviours. Either way, market share can result in different but related outcomes depending on whether competitor's pressure or consumer's pressure forces drive the market share. On the basis of the above argument and depending on the prevailing balance of demand pull vs. supply push, organizational motivations for innovation capability can include an economic expectation of enhancing efficiency, a regulatory response of 
ensuring compliance and a normative objective of attaining legitimacy (Rahim et al,2007).

Hypothesis 1: Intellectual capital of firm has positive and significant effect on innovation capability.

Hypothesis 2: Intellectual capital and Organizational Motivation of firm has positive and significant influence on innovation capability. potentially affect the outcomes of this study were used Firm size and Firm age as control variables. large organizations may be more likely to develop innovative capabilities owing to their extensive resource bases ; however, smaller organizations may be more innovative owing to their flexibility. The nature of the organizations and employee contribution are competing in environment control which is known to

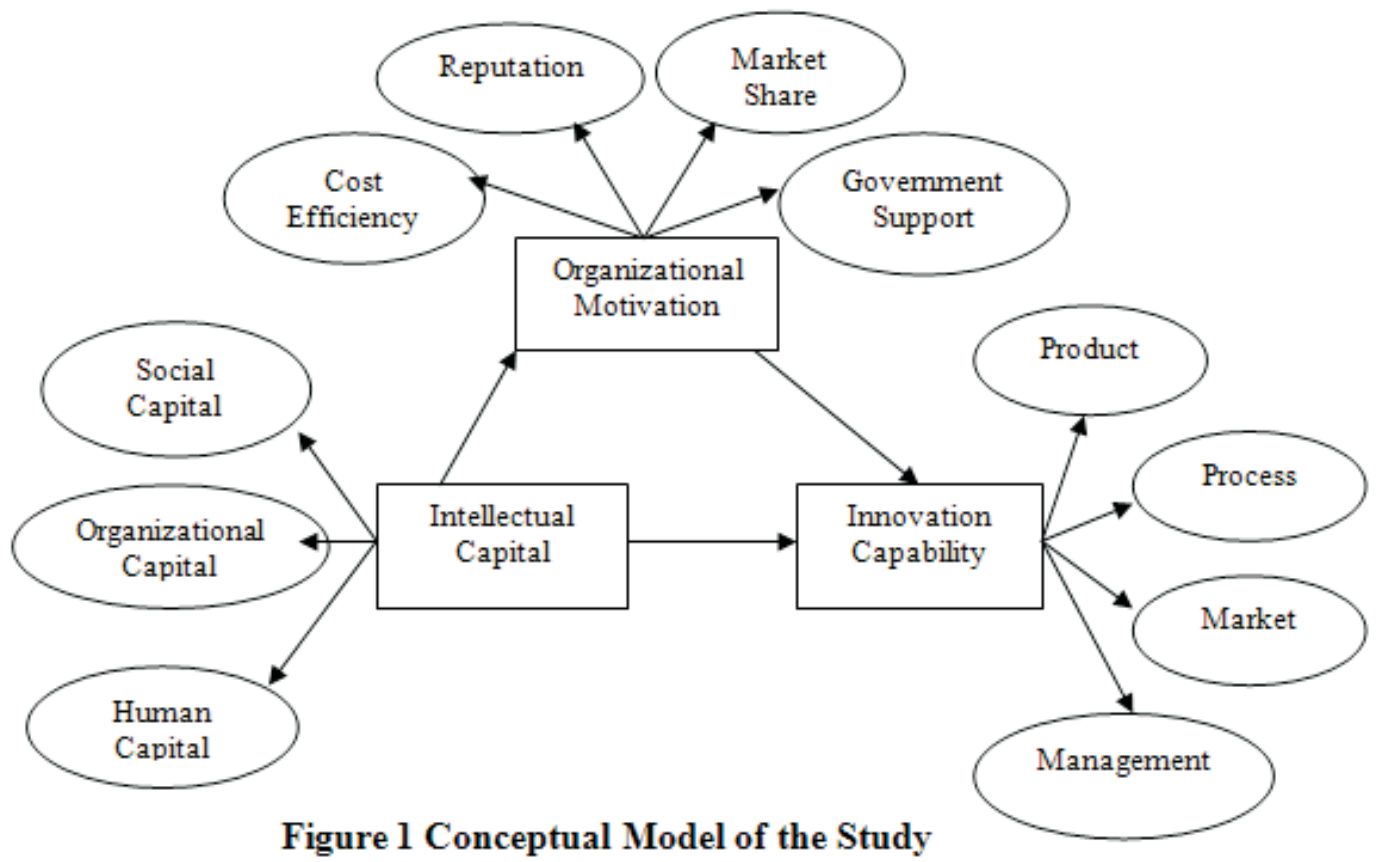

Hypothesis 3: Organizational influence their innovative capabilities. motivation will mediate the relationship between Intellectual capital and innovation capability.

3. METHODOLOGY

A sample of 800 manufacturing enterprises of various sizes ranging from Several firm-level variables that can small, medium, and large was drawn 
from the list of export association and Board of investment of Sri Lanka. The questionnaire designed for this study was pre-tested and finalized before it was utilized for survey. The questionnaire along with a letter of request addressed to the chief executive officer and senior managers of each firm was mailed to the sampled firms. The data for the analysis were obtained through a mail questionnaire survey conducted during in 2012 -2014. The study has received 478 filled questionnaires from $\mathrm{CEO}$ and Senior Manager of 246 manufacturing enterprises, getting a response rate of 60 percent. Since 16 responses were uncompleted, after deleting missing data or unfilled some cases, the total useable responses to 462 cases were retained for analysis.

Items for the survey questionnaire were developed after an extensive review of the relevant literature on intellectual capital in manufacturing industries, Innovation capability, and firm performance, organizational motivation in general. The total number of items included in the survey was 42 including those items that were used in this study and other items that were used in order to tap into other research questions. Where applicable, items that were used in previous studies were adapted to the purpose of this study to ensure validity of survey measures.

First, multiple linear regression analysis is used for testing the hypotheses relating to within manufacturing. Second, the structural equation modeling (SEM) analysis is employed to measure any mediate effects of organizational motivation and statistically significant differences in innovation capability in the manufacturing industry in the light of intellectual capital and innovation capability. In addition, descriptive statistics are used to analyses and interpret the statistical attributes of the population, sample and variables. In this paper, SPSS 21.0 statistical analysis software and AMOS 20.0 structural equation modeling techniques were used as a data analysis tool.

\section{FINDINGS AND \\ DISCUSSIONS}

\subsection{Sample Description}

The demographic percentages are based on the questionnaires without missing data. As mentioned before, the respondents come from a variety of different organizations with $59.7 \%$ male and $40.3 \%$ female. Their ages ranged from 20 to 59 , around more than $50 \%$ from 35-59 years old. $62.1 \%$ were 
married and more than $72 \%$ have bachelor and professional degree, around $12 \%$ have master degree in their discipline. $75 \%$ of them have at least 5 years' experience in same enterprises. Their functions include accounting, advisory, engineering, finance, human resources, and marketing, operations, research, and technology services. Respondents indicated that they come from organizations with sizes in the range of 100-over 1000 full-time equivalent employees. Around $78 \%$ are come from 501-2000 employee size of firm.

All industry sectors were fairly well represented by sample firms, while the textile and apparel sector accounted for nearly 33 percent of all firms, indicating its dominance in the current manufacturing as this sector has contributed to the $52 \%$ of the export earnings of country. The majority of firms were private companies limited (58.2 percent) with others comprising public companies limited (27.7 percent). This indicate that private company limited has become the most popular form of business organization among manufacturing firms in Sri Lanka. The size of firm was measured in terms of number of employee. The number of small, medium, and large firms included in the respondent sample were 13.2 percent, 38.5 percent, and 48.3 percent respectively. This grouping was based on a widely used criterion of defining manufacturing firms with 1-100 employees as a small-scale industry, 101-500 employees as a medium-scale industry, and those with more than 501 employee as a large-scale industry.

In the industrial composition of sample, Textiles, Wearing Apparel and Leather Products firms represented the biggest sector in sample (33\%), whilst $15 \%$ are involved in Chemical, Petroleum, Coal, Rubber and Plastic Products firms and $14 \%$ firms specialized in Food, Beverages and Tobacco Products. The other firms in the survey were spread across a number of different sectors, including Wood and Wood Products (8\%), Paper Products, Publishing and Printing (7\%), Fabricated Metal Products, Machinery and Transport Equipment (7\%), Non-Metallic Mineral Products $(6 \%)$, and $10 \%$ of the firms surveyed operate in non-specified manufactured products (Not Elsewhere Specified).

The sample composition with respect to the firm age described in Table 4 demonstrates that the majority of firms (59.4\%) were established in the period of 
more than 20 years old. $17.7 \%$ of firms are less than 10 years old, $22.9 \%$ are between 11-20 years old, and 27.3\% were established 21-30 years ago. Only $2.2 \%$ have been established for more than 40 years. In this study, the firms were divided into two groups: older and younger. The firms established before 1995 were denoted as older firms, and the firms established since 1995 as younger. This division allowed the sample to be split into two groups of approximately the oldest of $59.4 \%$ and youngest of $40.6 \%$. When respect to the sales of firms which was measured in terms of annual sales, 34.0 percent of the firms had sales less than 1 million US dollars while highest 38.5 percent of firms had sales ranging from 1-10 million US dollars, 15.6 percent of firms had sales 11-20 million dollars, and only 11.7 of firms had an annual sales more than 21 million dollars.

\subsection{The Reliability, and Validity Analysis}

The factor analysis with varimax rotation of 11 variables yielded three significant factors which explained $65 \%$ percent of total variance. These factors were also considered satisfactory according to the reliability test of Cronbach alpha with a value of greater than 0.6. A one-factor solution in which all the items had high loadings (average loading $=0.742$ ) and the single factor explaining $55 \%$ of the variance was obtained and the components of intellectual capital as human capital, social capital, and organizational capital had high factor loading (average loading more than 0.658), and the Cronbach $\alpha$ value $(\mathrm{HC}=0.869, \mathrm{SC}=0.865$, and $\mathrm{OC}=$ 0.878 ) respectively higher than standard. The component of intellectual capital had composite reliability more than 0.9 . As general guideline, composite reliability of 0.7 or higher are considered as good.

There are several reasons to believe that organizational motivation will be more conductive to innovation capability in organization with higher levels of intellectual capital. However, a onefactor solution with the single factor explaining $43 \%$ of the organizational motivation variance emerged, with an average item loading of 0.658 . The Cronbach $\alpha$ coefficient value of 0.809 , and also the composite reliability (CR) value of 0.885 higher and considered as good.

Innovation capability refers to the firm's ability to transform and knowledge and ideas into new products, processes systems for the benefit of the firms 
(Lawson and Samson, 2001). However, a one-factor solution with the single factor explaining $44 \%$ of the innovation capability variance emerged, with an average item loading of 0.666 . The Cronbach $\alpha$ coefficient value of 0.874 . And also the composite reliability (CR) value of 0.908 higher and considered good.

\subsection{Model Analysis}

Reliability and validity analysis is to test the hypothesis preparatory work to ensure that the variables were used to test the hypothesis that both have met the requirements. Researcher assume direct model validation, found intellectual capital of the enterprise has a certain role in influence on innovation capability, in motivation has strongest coefficient of $0.483, p<0.05$; intellectual capital has the impact coefficient of $0.313, p<0.05$ significantly. Here researcher found that the intellectual capital of the firm has the most significant influence on innovation capability, this also confirms the intellectual capital of the human, social, and organizational capital as the company's core research ideas. Another thing that the organizational motivation have most significant impact on innovation capability, this is different than expected, indicating that the pursuit of intellectual capital and innovation capability and some influence between intellectual capital and innovation capability. As the Table 1 shown, one way ANOVA was utilized to determine

\section{Table 1 ANOVA Results of Group differences}

\begin{tabular}{cllll}
\hline \multirow{2}{*}{ Factor Variables } & $\begin{array}{l}\text { Small } \\
\text { Firms }\end{array}$ & $\begin{array}{l}\text { Medium } \\
\text { Firms }\end{array}$ & $\begin{array}{l}\text { Large } \\
\text { Firms }\end{array}$ & Significant \\
\hline IC- HC & 3.32 & $3.61^{*}$ & $3.91^{*}$ & $0.001^{* *}$ \\
SC & $3.91^{*}$ & $3.89^{*}$ & $4.01^{*}$ & $0.000^{* *}$ \\
OC & 4.21 & $4.02^{* *}$ & $4.22^{* *}$ & $0.000^{* *}$ \\
OM-MS & 3.50 & $3.99^{*}$ & $3.59^{*}$ & $0.002^{*}$ \\
GS & $3.42^{* *}$ & $3.92^{* *}$ & $3.83^{* *}$ & $0.000^{* *}$ \\
RE & 4.01 & 4.21 & $4.12^{*}$ & $0.007^{*}$ \\
CE & $2.63^{*}$ & $3.07^{*}$ & $2.85^{*}$ & $0.004^{*}$ \\
INC-PD & 2.43 & $2.56^{* *}$ & $2.72^{*}$ & $0.000^{*}$ \\
PC & 3.42 & $3.60^{*}$ & $3.65^{*}$ & $0.000^{*}$ \\
MK & $3.22^{*}$ & $3.78^{*}$ & $3.87^{*}$ & $0.000^{* *}$ \\
MG & 2.35 & $2.54^{*}$ & 2.73 & $0.000^{*}$ \\
* P< 05; and ** P<.01 & \multicolumn{5}{l}{} \\
which the role of the firms organizational \\
Journal of Business Studies
\end{tabular}


whether there was a statistically significant difference between the means of factors among the three groups of firms.

\subsection{Mediation Analysis.}

While the Baron and Kenny (1986) procedure is the most commonly used method in organizational research, MacKinnon and his colleagues (2002) compared 14 methods that test mediation effects and found that the procedure has low statistical power and that the best balance of Type I error and statistical power in tests of mediation is achieved by the Sobel (1982) test. In this paper, the researcher relied on three methods to test for mediation - the Baron and Kenny (1986) procedure, the test, and path analysis. In the case of simple mediation, the indirect effect of the independent variable on the dependent variable is defined as the cross-product of the independent variable-mediator path and the mediator-dependent variable path and the significance test associated with the product term. According to testing the hypothesis of no difference between the total effect and the direct effect more directly addresses the mediation hypothesis than do the series of regression analyses proposed by Baron and Kenny (1986).

Hypothesis $H 2$, and $H 2 a$ proposed that the relationship between intellectual capital and innovation capability is mediated by organization motivation.

Table 2 Summary Correlation Matrix ( $\mathrm{N}=462)$

\begin{tabular}{|c|c|c|c|c|c|c|c|c|c|c|c|c|c|c|}
\hline Variables & $M$ & $S D$ & $y_{1}$ & $y_{2}$ & $y_{3}$ & $y_{4}$ & $x_{1}$ & $x_{2}$ & $x_{3}$ & $m_{1}$ & $m_{2}$ & $m_{3}$ & $m_{4}$ & $c_{l}$ \\
\hline $\begin{array}{l}y_{1} \text { Product } \\
\text { Innovation }\end{array}$ & 4.218 & 0.834 & - & & & & & & & & & & & \\
\hline $\begin{array}{l}y_{2} \text { Process } \\
\text { Innovation }\end{array}$ & 2.687 & 0.997 & $0.769^{* *}$ & - & & & & & & & & & & \\
\hline $\begin{array}{l}y_{3} \text { Market } \\
\text { Innovation }\end{array}$ & 2.217 & 0.799 & $0.782^{* *}$ & $0.658^{* *}$ & - & & & & & & & & & \\
\hline $\begin{array}{c}y_{4} \text { Manageme } \\
\text { ntInno }\end{array}$ & 3.585 & 1.188 & $0.691^{* *}$ & $0.591^{* *}$ & $0.648^{* *}$ & - & & & & & & & & \\
\hline $\begin{array}{c}x_{1} \text { Human } \\
\text { Capital }\end{array}$ & 3.956 & 0.757 & $0.295^{* *}$ & $0.327^{* *}$ & $0.362^{* *}$ & $0.157^{* *}$ & - & & & & & & & \\
\hline $\begin{array}{c}x_{2} \text { Social } \\
\text { Capital }\end{array}$ & 4.013 & 0.699 & $0.504^{* *}$ & $0.443^{* *}$ & $0.551^{* *}$ & $0.489^{\circ *}$ & $0.495^{* *}$ & - & & & & & & \\
\hline $\begin{array}{r}x_{3} \text { Organizatio } \\
\text { nal Capital }\end{array}$ & 4.053 & 0.749 & $0.595^{* *}$ & $0.527^{* *}$ & $0.562^{* *}$ & $0.557^{* *}$ & $0.487^{* *}$ & $0.399^{* *}$ & - & & & & & \\
\hline $\begin{array}{l}m_{I} \text { Market } \\
\text { Share }\end{array}$ & 3.996 & 0.848 & $0.504^{* *}$ & $0.443^{* *}$ & $0.551^{* *}$ & $0.489^{* *}$ & $0.387^{* *}$ & $0.199^{* *}$ & 0.001 & - & & & & \\
\hline $\begin{array}{r}m_{2} \text { Governme } \\
\text { nt Support }\end{array}$ & 3.973 & 0.748 & $0.591^{* *}$ & $0.382^{* *}$ & $0.258^{* *}$ & $0.548^{* *}$ & $0.582^{* *}$ & $0.628^{* *}$ & $0.648^{* *}$ & $0.458^{* *}$ & - & & & \\
\hline $\begin{array}{l}m_{3} \text { Reputation } \\
\text { Status }\end{array}$ & 3.218 & 0.834 & $0.369^{* *}$ & $0.291^{* *}$ & $0.504^{* *}$ & $0.443^{* *}$ & $0.351^{* *}$ & $0.489^{* *}$ & $0.287^{* *}$ & $0.299^{* *}$ & 0.109 & - & & \\
\hline $\begin{array}{l}m_{4} \text { Cost } \\
\quad \text { Efficiency }\end{array}$ & 2.687 & 0.997 & $0.782^{* *}$ & $0.658^{\circ *}$ & $0.691^{* *}$ & $0.782^{* *}$ & $0.558^{* *}$ & $0.348^{* *}$ & $0.482^{* *}$ & $0.618^{\circ *}$ & $0.448^{* *}$ & $0.358^{* *}$ & - & \\
\hline$c_{1}$ Age & 2.217 & 0.799 & $-.194^{* *}$ & -.089 & $-.133^{*}$ & -.029 & -.088 & $0.190^{* *}$ & $-.456^{\circ *}$ & $-.280^{* *}$ & $0.458^{* *}$ & $0.287^{* *}$ & $0.186^{* *}$ & - \\
\hline$c_{2}$ Size & 3.585 & 1.188 & $-.468^{* *}$ & $-.275^{* *}$ & $-.338^{* *}$ & $-.397^{* *}$ & $-.354^{* *}$ & $-.456^{* *}$ & $-.280^{* *}$ & $0.458^{* *}$ & $-.456^{* *}$ & $0.280^{* *}$ & $0.328^{* *}$ & $0.287^{* *}$ \\
\hline
\end{tabular}


Table 3: Model Summary of Intellectual Capital and Innovation Capability

\begin{tabular}{lccc} 
Variables & Model 1 & Model 2 & Model 3 \\
\hline $\boldsymbol{x}_{1}$ Human Capital & $0.230^{* *}$ & $0.435^{* *}$ & $0.387^{* *}$ \\
$\boldsymbol{x}_{2}$ Social Capital & $0.202^{* *}$ & 0.197 & $0.368 * *$ \\
$\boldsymbol{x}_{3}$ Organizational Capital & $0.414^{* *}$ & $0.392^{*}$ & $0.070^{* *}$ \\
$\boldsymbol{m}_{1}$ Market Share & & $a$ & $0.451^{*}$ \\
$\boldsymbol{m}_{2}$ Government Support & & $a$ & $0.128 * *$ \\
$\boldsymbol{m}_{3}$ Reputation Status & & $a$ & $0.122^{* *}$ \\
$\boldsymbol{m}_{4}$ Cost Efficiency & & $a$ & $0.154 *$ \\
$\boldsymbol{c}_{1}$ Age & 0.141 & -0.056 & -0.035 \\
$\boldsymbol{c}_{2}$ Size & $-0.129 * *$ & -0.495 & -0.009 \\
${ }^{B}$ & 0.503 & 0.052 & 0.528 \\
$R^{2}$ & 0.604 & 0.614 & 0.698 \\
$F$ & $461.31 *$ & $238.97 *$ & $334.35 *$ \\
\hline${ }^{*} p<0.01$, and ${ }^{* *} p<0.05$ & & &
\end{tabular}

The results in Table 3 shows that intellectual capital has a significant impact on innovation capability to satisfy the first condition of the Baron and Kenny (1986) procedure for establishing mediation. The testing the indirect effect of intellectual capital on innovation capability requires a significant relationship between intellectual capital and organization motivation (condition 2) and between organization motivation and innovation capability in the presence of innovation capital (condition 3). There was support for the second condition based on the results of Hypothesis $H 1$ reported in the Journal of Business Studies

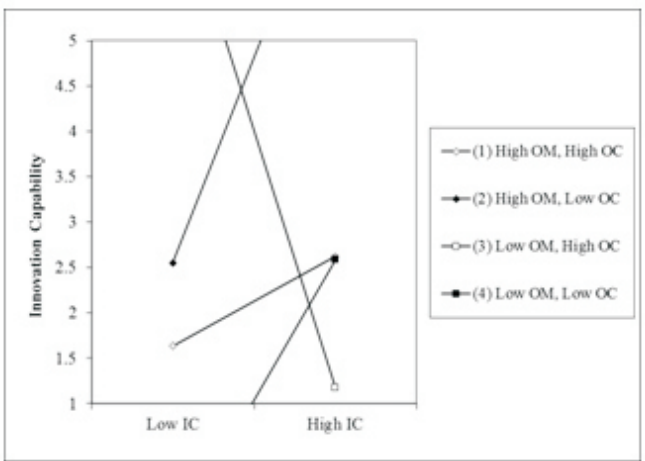

Figure 2 Mediating Impact of Organization Motivation

preceding section (Table 2). Table 3 shows that organization motivation and innovation capability are also significantly related in the presence of intellectual capital, that satisfying the third condition. Based on the support 
found for both of these relationships, the presence of an indirect relationship is supported between intellectual capital and innovation capability through organization motivation. Sobel (1982) test was further conducted to test the significance of the indirect effect of intellectual capital on innovation capability. The result of this test provided further support for the significance of such an indirect effect (Sobel $z=4.263, p<.05$ ). Based on these results, Hypothesis $H 2 a$ was supported.

The hypothesized model, holds up well when tested against the confirmatory sample of 462 of manufacturing industry of Sri Lanka. While the $X^{2}$ value of 5.609 is statistically significant with 7 degree of freedom, the root mean squared error of approximation is (RMSEA $=0.000$, and RMR $=0.004$ ) which suggests a good fit since it is below the critical threshold of 0.08. Further, the Normed Fit Index $(\mathrm{NFI}=0.997)$, the Goodness of Fit Index $(\mathrm{GFI}=0.995)$, the Incremental Fit Index (IFI $=1.001)$, and the Confirmatory Fit Index $(\mathrm{CFI}=1.000)$ are all between 0.99 and 1.0, suggesting that the research model fits the observed data well.

Figure 2 illustrates the positive and disordinal mediating impact of organization motivation on the relationship between intellectual capital and innovation capability. Visual inspection of Figure 2 suggests that when firms possess high levels of motivation, the relationship between intellectual capital and innovation capability is positive and under low levels of organization motivation the relationship between intellectual capital and innovation capability is negative. Finally, this positive impact of organizational motivation on the relationship between intellectual capital and innovation capability suggests that the relationship is negative under low levels of organizational motivation, and high level of organizational characteristics. There is a positive relationship between intellectual capital and innovation capability under high levels of organizational motivation, and high or low level of organizational characteristics.

The results of correlation analysis summarized Table 2 indicated that the significant effects of human capital, social capital, and organizational capital. The patterns of relationship between the intellectual capital, organizational motivation, and innovation capability are, in general, quite similar among the whole sample, and the sub-samples of 
younger and older firms. However, there is a difference between the younger and older firms. The effects of organizational capital and social capital are stronger among the older firms than among the younger firms. According to the corresponding correlation coefficients, human capital is more important among the younger firms. The mediation effects of reputation status and cost efficiency are stronger among the older firms than younger firms, same as market share and government support are stronger among the younger firms.

In sum, the results from this section as well as the plots of interactions lead to an empirical conclusion which is somewhat different from the conclusions drawn in earlier sections which pointed to a direct relationship between intellectual capital and innovation capability. Based on the results of this last section, it seems that in the presence of intellectual capital and organizational motivation, does not predict innovation capability and that this relationship becomes positive, contrary to predictions, under conditions of low organization motivation and low intellectual capital, and consistent with predictions, under conditions of high organization motivation.

\section{CONCLUSIONS AND RECOMMENDATIONS}

This finding highlights that when the manufacturing industry creates an organizational motivation culture and innovation-oriented culture, that will facilitates and better firm performance from better innovation. In this study, we found that intellectual capital facilitate by organizational motivation that lies outside and inside of the firm have an indirect effect on innovation capability. These practices were positively related to innovation capability, which, in turn, was related to firm performance. While the positive relationship between intellectual capital and innovation capability was a strong and consistent finding throughout all the analyses performed. Results also supported a direct relationship between intellectual capital and innovation capability. There was a controlling affects of organizational characteristics such as age and size in strengthening the relationship between intellectual capital and innovation capability. The theoretical and practical implications of these findings as well as the limitations of this study are discussed below.

Overall, the findings of this study extend both knowledge management and innovation management literatures in 
important ways. First of all, it provides empirical support for the existence of a dual path - internal and external through which firm can gain competitive advantage in markets through organizational motivation and innovation. Yet, it shows that organizational motivation is more critical for firm' innovation capability compared to organizational characteristics. Second, it shows that the knowledge management, and resource base view framework are a useful theory for opening up the black box between intellectual capital, innovation and performance in export oriented firms.

The skills level of Sri Lankan workers as a positive factor when considering the apparel manufacturing industry. Sri Lanka has a highly trainable work force in the Asian region that has much higher literacy rate which is similar to the developed countries . Considering the motivation level of the workers, to work in the apparel manufacturing industry at the operator level, it should be noted that having apparel industry is the major employment provider for Sri Lankan economy. Modern management practice in manufacturing industry considers employees as a valuable asset. Most of the organizations have a good level of employer-employee relationships.

\section{REFERENCES}

Baron, R. M., \& Kenny, D. A. (1986). The moderator-mediator variable distinction in social psychological research: Conceptual, strategic, and statistical considerations. Journal of Personality and Social Psychology, 51(6), 1173.

Bontis, N. (1998). Intellectual capital: an exploratory study that develops measures and models. Management Decision, 36(2), 63-76.

Bontis, N. (1999). Managing organizational knowledge by diagnosing intellectual capital: framing and advancing the state of the field. International Journal of Technology Management, 18(5-8), 433-462. doi:10.1504/ijtm.1999.002780

Cohen, W. M., \& Levinthal, D. A. (1990). Absorptive capacity: a new perspective on learning and innovation. Administrative Science Quarterly, 35(128-152).

Edvinsson, L. (1997). Developing intellectual capital at Skandia. Long Range Planning, 30(3), 366-373.

Hall, R. (1992). The strategic analysis of intangible resources. Strategic Management Journal, 13(2), 135-144.

Helfat, C. E., \& Peteraf, M. A. (2003). The dynamic resource-based view: Capability lifecycles. Strategic Management Journal, 24(10), $997-$ 1010. doi:10.1002/smj.332

Henderson, R., \& Cockburn, I. (1994). Measuring competence? Exploring firm effects in pharmaceutical research. Strategic 
Management Journal, 15(S1), 63-84.

Kaufmann, L., \& Schneider, Y. (2004). Intangibles: a synthesis of current research. Journal of intellectual capital, 5(3), 366-388.

Kelegama, S., \& Wijayasiri, J. (2004). Overview of the garment industry in Sri Lanka. Ready Made Garment Industry in Sri Lanka: Facing the Global Challenge, Institute of Policy Studies, Colombo.

March, J. G. (1991). Exploration and Exploitation in Organizational Learning. Organization Science, 2(1), 71-87.

Nahapiet, J., \& Ghoshal, S. (1998). Social capital, intellectual capital, and the organizational advantage. Academy of Management Review, 23(2), 242-266. doi:10.2307/259373

Petty, R., \& Guthrie, J. (2000). Intellectual capital literature review: measurement, reporting and management. Journal of intellectual capital, 1(2), 155-176.

Porter, M. E. (1998). Clusters and the new economics of competition. Harvard Business Review, 76(6), 77-+.

Preacher, K. J., \& Hayes, A. F. (2004). SPSS and SAS procedures for estimating indirect effects in simple mediation models. Behavior Research Methods, Instruments, \& Computers, 36(4), 717-731.

Roos, G., Bainbridge, A., \& Jacobsen, K. (2001). Intellectual capital analysis as a strategic tool. Strategy \& Leadership, 29(4), 21-26.

Sivalogathasan, V., \& Wu, X. (2014). Innovation Needs The Motivation: Organization Motivation Mediate between Intellectual Capital and Innovation capability of the Textile \& Apparel Industry in Sri Lanka. Management Matters Journal, University of
Rajarada, SriLanka, I(1).

Baron, R. M., \& Kenny, D. A. (1986). The moderator-mediator variable distinction in social psychological research: Conceptual, strategic, and statistical considerations. Journal of Personality and Social Psychology, 51(6), 1173.

Bontis, N. (1998). Intellectual capital: an exploratory study that develops measures and models. Management Decision, 36(2), 63-76.

Bontis, N. (1999). Managing organizational knowledge by diagnosing intellectual capital: framing and advancing the state of the field. International Journal of Technology Management, 18(5-8), 433-462. doi:10.1504/ijtm.1999.002780

Cohen, W. M., \& Levinthal, D. A. (1990). Absorptive capacity: a new perspective on learning and innovation. Administrative Science Quarterly, 35(128-152).

Edvinsson, L. (1997). Developing intellectual capital at Skandia. Long Range Planning, 30(3), 366-373.

Hall, R. (1992). The strategic analysis of intangible resources. Strategic Management Journal, 13(2), 135-144.

Helfat, C. E., \& Peteraf, M. A. (2003). The dynamic resource-based view: Capability lifecycles. Strategic Management Journal, 24(10), 9971010. doi:10.1002/smj.332

Henderson, R., \& Cockburn, I. (1994). Measuring competence? Exploring firm effects in pharmaceutical research. Strategic ManagementJournal, 15(S1), 63-84. 
Kaufmann, L., \& Schneider, Y. (2004). Intangibles: a synthesis of current research. Journal of intellectual capital, 5(3),366-388.

Kelegama, S., \& Wijayasiri, J. (2004). Overview of the garment industry in Sri Lanka. Ready Made Garment Industry in Sri Lanka: Facing the Global Challenge, Institute of Policy Studies, Colombo.

March, J. G. (1991). Exploration and Exploitation in Organizational Learning. Organization Science, 2(1), 71-87.

Nahapiet, J., \& Ghoshal, S. (1998). Social capital, intellectual capital, and the organizational advantage. Academy of Management Review, 23(2), 242-266. doi:10.2307/259373

Petty, R., \& Guthrie, J. (2000). Intellectual capital literature review: measurement, reporting and management. Journal of intellectual capital, 1(2), 155-176.

Porter, M. E. (1998). Clusters and the new economics of competition. Harvard Business Review, 76(6), 77-+.

Preacher, K. J., \& Hayes, A. F. (2004). SPSS and SAS procedures for estimating indirect effects in simple mediation models. Behavior Research Methods, Instruments, \& Computers, 36(4), 717-731.

Roos, G., Bainbridge, A., \& Jacobsen, K. (2001). Intellectual capital analysis as a strategic tool. Strategy\&Leadership, 29(4), 21-26.

Sivalogathasan, V., \& Wu, X. (2014). Innovation Needs The Motivation: Organization Motivation Mediate between Intellectual Capital and Innovation capability of the Textile \& Apparel Industry in Sri Lanka.
Management Matters Journal, University of Rajarada, Sri Lanka, I(1).

Sobel, M. E. (1982). Asymptotic confidence intervals for indirect effects in structural equation models. Sociological methodology, 13(1982), 290-312.

Stewart, T. (1997). Intellectual Capital: The New Wealth of Organizations. Doubleday/ Currency, New York, NY.

Sveiby, K. E. (1998). Knowledge works: Managing intellectual capital at Toshiba. Administrative Science Quarterly, 43(4), 936-938.

Teece, D., Pisano G., Shuen, A. (1997). Dynamic capabilities and strategic management. Strategic ManagementJournal, 18,509-533.

Wu, X., Sivalogathasan, V., \& Xiong, L. (2013). Moderation effect on Innovation Capability: Intellectual Capital and Innovation Capability of the Apparel Industry in Sri Lanka. Paper presented at the The Ninth International Symposium on Global Manufacturing and China (GMC2013), Sep. 7-Sep. 8, 2013, Zhejiang University, Hangzhou, China.

Youndt, M. A., Subramaniam, M., \& Snell, S. A. (2004). Intellectual Capital Profiles: An Examination of Investments and Returns*. Journal of Management Studies, 41(2), 335361.

Zahra, S. A., \& George, G. (2002). Absorptive capacity: A review, reconceptualization, and extension. Academy of Management Review, 27(2), 185-203. doi:10.2307/4 134351 